Bài báo khoa học

\title{
Úng dụng viễn thám và GIS theo dõi quá trình đô thị hóa tại thành phố Hồ Chí Minh giai đoạn 1989-2019
}

\author{
Lâm Văn Hạo ${ }^{1 *}$, Lê Thị Pha Mi ${ }^{1}$ \\ ${ }^{1}$ Khoa Vật lý-Vật lý Kỹ thuật, Trường Đại học Khoa học Tự nhiên, ĐHQG-HCM \\ * Tác giả liên hệ: 1vhao@hcmus.edu.vn, Tel: +84-979617090
}

Ban Biên tập nhận bài: 26/10/2020; Ngày phản biện xong: 29/11/2020; Ngày đăng bài: 25/12/2020

Tóm tắt: Nghiên cứu này đã sử dụng phần mềm ENVI và ArcGIS giải đoán ảnh vệ tinh Landsat nhằm theo dõi quá trình đô thị hóa tại thành phố Hồ Chí Minh giai đoạn 1989-2019 thông qua các bề mặt không thấm, hệ số Kappa đạt trên 0,85 . Kết quả nghiên cứu cho thấy đô thị ở thành phố Hồ Chí Minh phát triển mạnh theo hướng mở rộng từ khu vực trung tâm ra ngoài vùng ven và có xu hướng tiến dần lên phía bắc, đông bắc và tây bắc thành phố, đặc biệt tập trung dọc theo các trục lộ chính ở khu vực ngoại thành, điều này được thể hiện qua diện tích mặt không thấm tăng 36431,7 ha tương ứng với tốc độ tăng trung bình 1214,4 ha/năm và bán kính khu vực đô thị được mở rộng từ 7 km lên 19 km.

Từ khóa: Mặt không thấm; Đô thị hóa; Thành phố Hồ Chí Minh; Viễn thám; GIS.

\section{Mở đầu}

Đô thị hóa là quá trình tập trung dân số vào các đô thị, là sự hình thành nhanh chóng các điểm dân cư đô thị trên cơ sở phát triển sản xuất và đời sống [1]. Đối với một quốc gia, đô thị hóa bao gồm hai quá trình, quá trình mở rộng các đô thị hiện có và quá trình hình thành các đô thị mới đồng thời đó là quá trình chuyển dịch cơ cấu kinh tế theo hướng giảm sản xuất nông nghiệp tăng sản xuất phi nông nghiệp [1]. Quá trình này thường làm thay đổi đặc tính của hệ sinh thái đô thị, được thể hiện qua việc biến đổi không gian của lớp phủ từ các hệ sinh thái tự nhiên sang hệ sinh thái chịu tác động của con người [2]. Hiện nay với sự gia tăng dân số nhanh chóng của các thành phố lớn do sự dịch chuyển dân cư từ nông thôn vào thành thị diễn ra mạnh mẽ làm cho vấn đề đô thị ngày càng phức tạp. Một mặt để đáp ứng nhu cầu nhà ở, đi lại, việc làm cho dân cư đòi hỏi phải thúc đẩy mạnh các công trình kiến trúc xây dựng, cơ sở hạ tầng và hoạt động trong lĩnh vực bất động sản nhưng mặt khác cũng phải đảm bảo môi trường sinh thái, cảnh quan đô thị. Vì vậy việc quản lý, giám sát các khu đô thị đang là vấn đề cấp bách được thực hiện, nhằm thông tin chính xác và cập nhật về tình trạng, xu hướng của các hệ sinh thái đô thị giúp các nhà quản lý theo dõi biến động và đề ra chiến lược để phát triển bền vững và cải thiện cuộc sống của cư dân đô thị. Thành phố Hồ Chí Minh là một trong những thành phố lớn với tốc độ phát triển nhanh, dân cư tập trung đông đúc với gần 9 triệu dân [3] do đó nghiên cứu quá trình đô thị hóa tại thành phố Hồ Chí Minh có ý nghĩa rất quan trọng. Mục tiêu của nghiên cứu là sử dụng ảnh vệ tinh Landsat để tính toán, phân loại và thành lập bản đồ phân bô đô thị từ đó theo dõi và đánh giá quá trình đô thị hóa theo không gian và thời gian.

Có hai cách để đánh giá mức độ đô thị hóa đó là dựa vào tỉ lệ phần trăm giữa số dân đô thị trên tổng số dân hoặc giữa diện tích đô thị trên diện tích của một vùng hay một khu vực [1]. Có nhiều phương pháp nghiền cứu khác nhau để nghiên cứu quá trình đô thị hóa thông qua diện tích đô thị trong đó viễn thám là một trong những phương pháp thường được sử 
dụng. Dữ liệu viễn thám có độ phân giải không gian cao và bao phủ mặt đất lớn cho phép thu nhận thông tin bề mặt Trái Đất, ngay cả những vùng mà con người không thể tiếp cận được, giúp giải quyết các vấn đề ở tầm vĩ mô về không gian trong thời gian ngắn [2]. Tuy nhiên do đặc tính phức tạp của lớp đô thị, việc nhầm lẫn giữa các phổ thường xuyên xảy ra, nên thường phải kết hợp thêm các dữ liệu GIS bổ trợ để mang lại kết quả tốt hơn [2]. Có rất nhiều công trình trong và ngoài nước sử dụng viễn thám để theo dõi quá trình đô thị hóa đó là dùng các phương pháp phân loại truyền thống dựa vào các kênh phổ có sẵn của các ảnh [4-6]; phân loại dựa vào các chỉ số như IBI, NDISI, MNDISI [7-13], ... hoặc kết hợp cả hai phương pháp trên $[2,14]$. Nghiên cứu này sử dụng phương pháp phân loại kết hợp các kênh ảnh sẵn có cùng với ảnh tỉ số và phân loại dựa vào các mặt không thấm (MKT) được xem là đặc trưng của lớp đô thị. Các MKT là các bề mặt nhân tạo như mái nhà, đường giao thông, lối đi bộ,...được bao phủ bởi các vật liệu không thấm như bê tông, nhựa đường, đá và các vật liệu xây dựng khác $[15,16]$. Các đối tượng này có gần mức phản xạ tại các bước sóng khác nhau nên có thể sử dụng phương pháp phân loại có kiểm định.

\section{Phương pháp nghiên cứu}

\subsection{Khu vục nghiên cúu}

Thành phố Hồ Chí Minh nằm trong khu vực chuyển tiếp giữa miền Đông Nam Bộ và Đồng bằng sông Cửu Long, bao gồm 19 quận và 5 huyện với tổng diện tích 2095,06 km² (Hình 1 ). Thành phố có địa hình thấp dần từ bắc xuống nam và từ đông sang tây, có điều kiện khí hậu đặc trưng của vùng nhiệt đới gió mùa cận xích đạo trong đó mùa mưa từ tháng 5 đến tháng 11 và mùa khô từ tháng 12 đến tháng 4 năm sau [17]. Theo kết quả thống kê điều tra dân số năm 2019 thì dân số thành phố khoảng gần 9 triệu người, mật độ dân số trung bình 4363 người $/ \mathrm{km}^{2}$ và tỉ lệ dân số thành thị chiếm gần $80 \%$ [3].

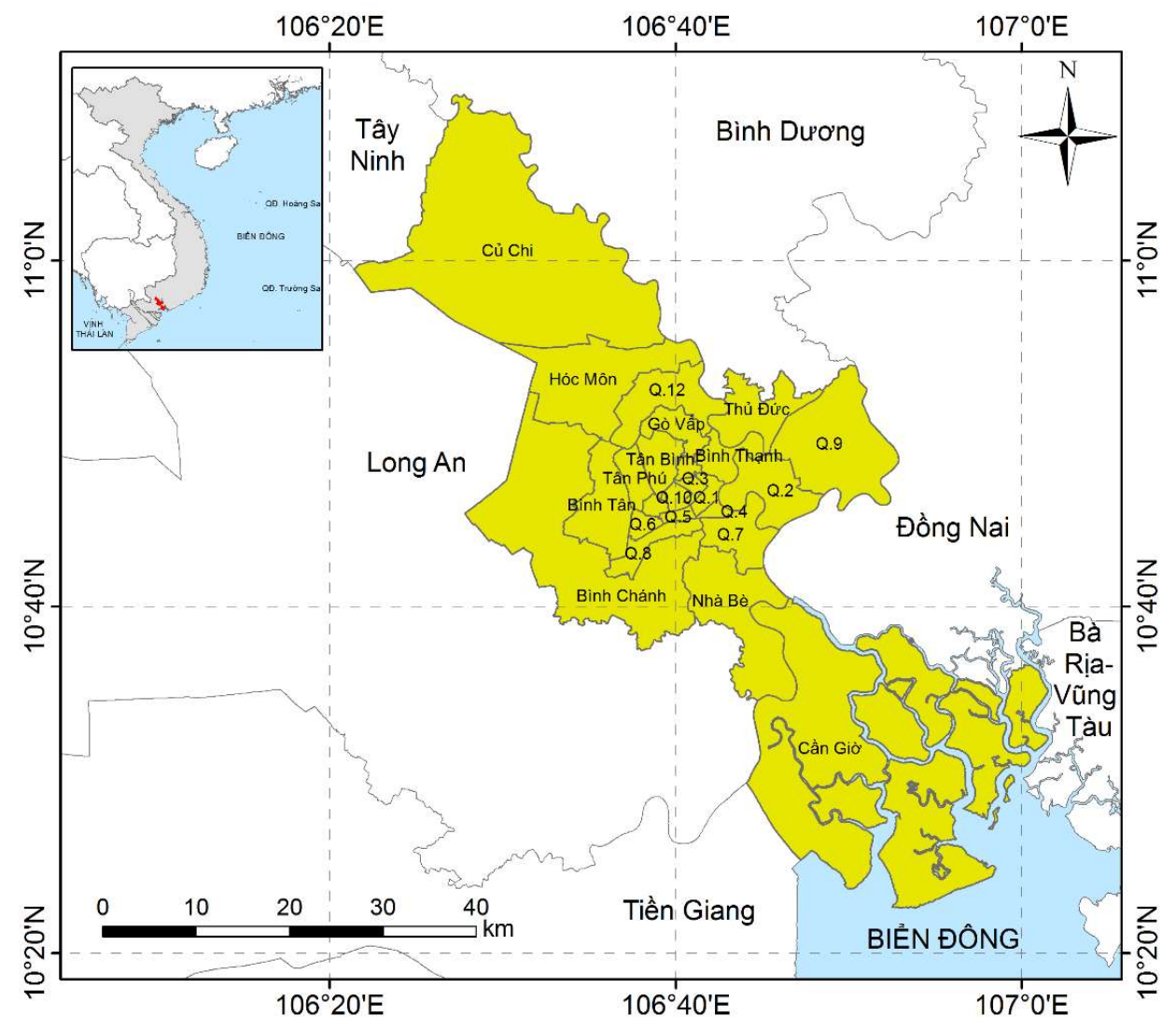

Hình 1. Bản đồ khu vực nghiên cứu. 


\subsection{Dũ liệu nghiên cứu}

Dữ liệu sử dụng trong nghiên cứu bao gồm: Dữ liệu ảnh vệ tinh đa phổ Landsat gồm Landsat 5 và Landsat 8 được lấy từ Liên đoàn khảo sát địa chất Hoa Kỳ vào các thời điểm 01/02/1989, 09/01/1998, 11/02/2010 và 19/01/2019 (Bảng 1) [18]. Dữ liệu ảnh được chọn vào thời điểm mùa khô để đảm bảo ảnh không bị ảnh hưởng của mây. Các kênh phổ của ảnh Landsat 5 và Landsat 8 nằm trong dải khả kiến và hồng ngoại; Dữ liệu vector chứa ranh giới của khu vực thành phố Hồ Chí Minh; Dũ̃ liệu ảnh được lấy trên Google Earth nhằm xác định các yếu tố thực phủ, giúp lựa chọn chính xác các điểm khống chế, thuận lợi cho việc hiệu chỉnh hình học cũng như phân loại; Dữ liệu khảo sát thực địa bao gồm 70 điểm mẫu được khảo sát vào năm 2018 với các loại thực phủ khác nhau được thể hiện trong Hình 2 (25 mẫu MKT, 25 mẫu mặt thấm (MT) và 20 mẫu mặt nước).

Bảng 1. Dữ liệu ảnh vệ tinh Landsat được sử dụng trong nghiên cứu [18].

\begin{tabular}{clcc}
\hline STT & Loại ảnh Landsat & Ngày thu ảnh & Độ phân giải không gian (m) \\
\hline 1 & Landsat 5 TM & $01 / 02 / 1989$ & 30 \\
2 & Landsat 5 TM & $09 / 01 / 1998$ & 30 \\
3 & Landsat 5 TM & $11 / 02 / 2010$ & 30 \\
4 & Landsat 8 OLI_TIRS & $19 / 01 / 2019$ & 30 \\
\hline
\end{tabular}

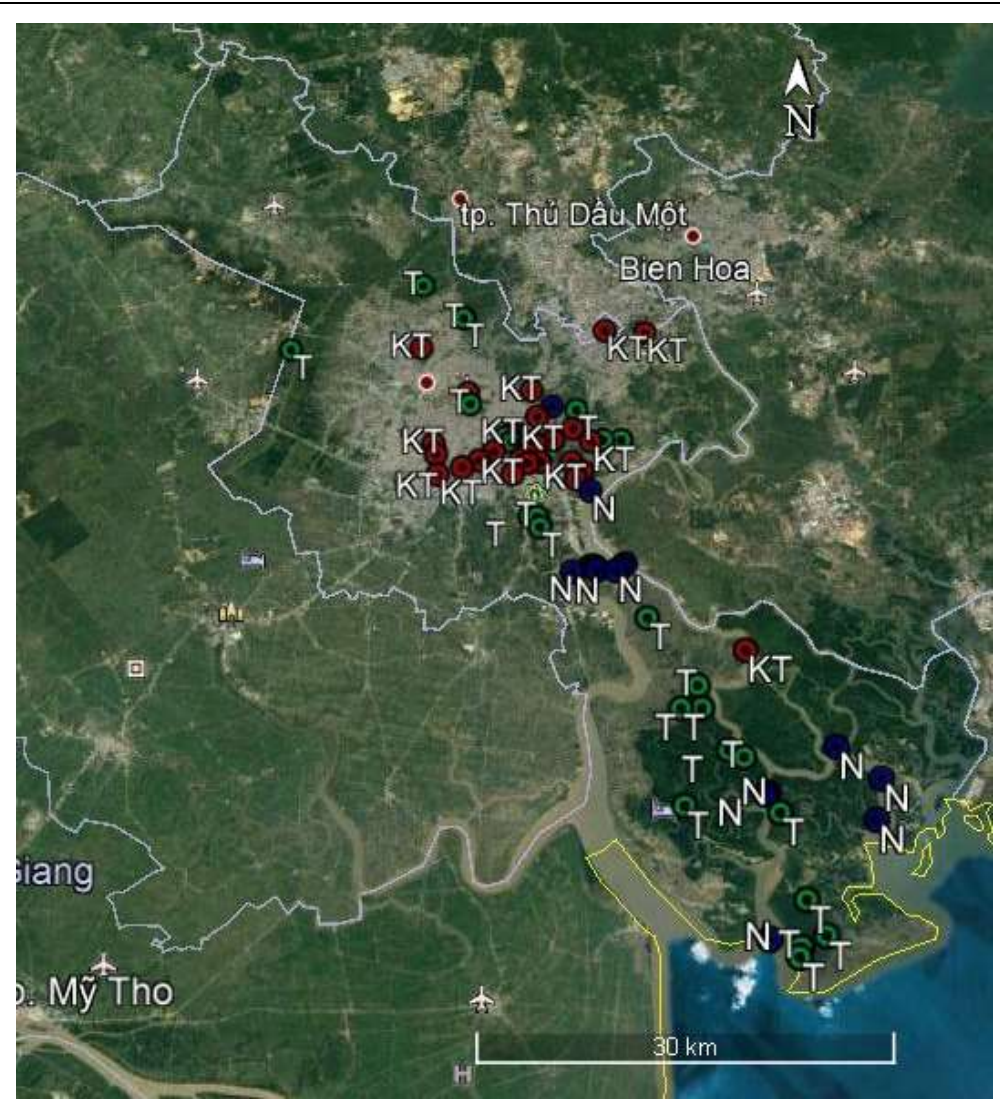

Hình 2. Vị trí các điểm mẫu khảo sát năm 2018.

\subsection{Phưong pháp nghiên cúu}

Nghiên cứu này phân loại lớp đô thị dựa vào đặc tính của MKT được thực hiện dựa trên viễn thám và GIS theo quy trình như Hình 3 . 


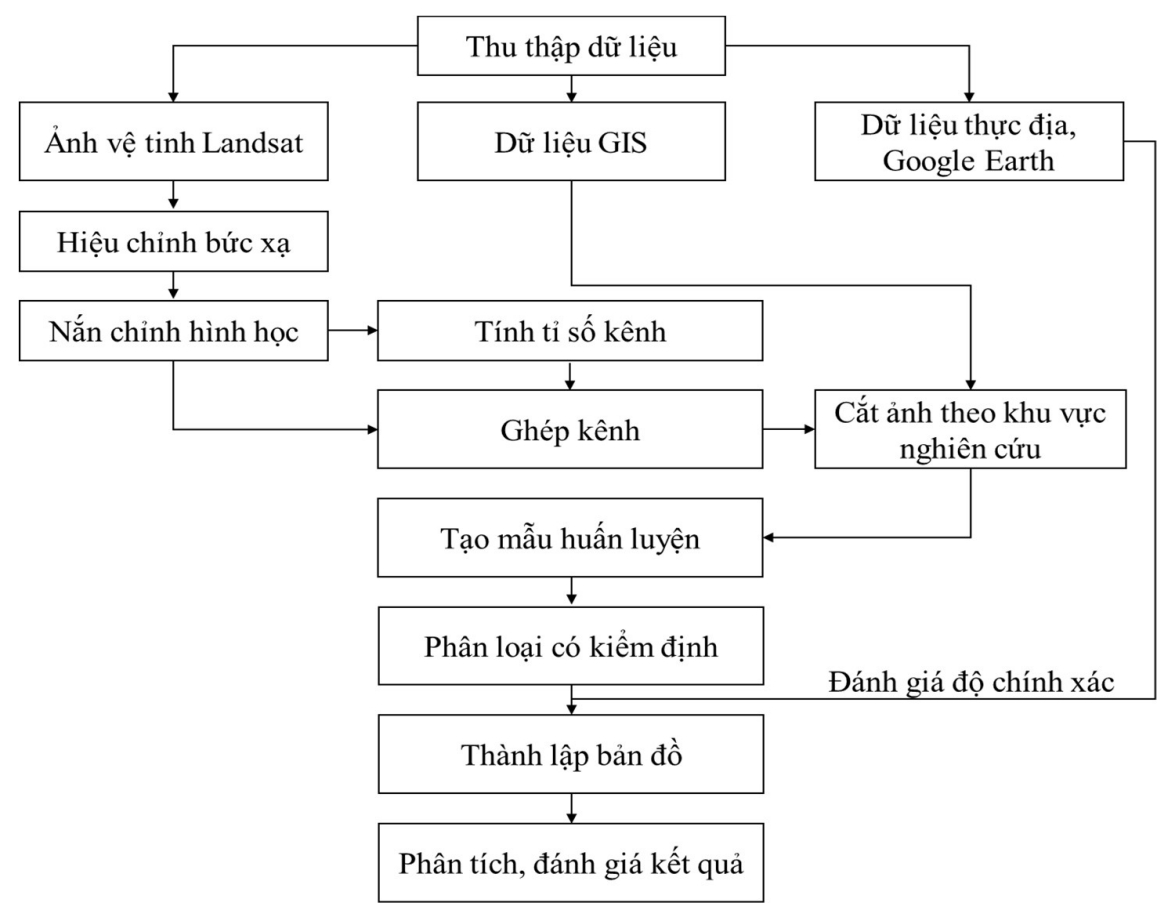

Hình 3. Sơ đồ quy trình thành lập bản đồ đô thị hóa.

\section{Viễn thám}

Dữ liệu ảnh vệ tinh Landsat sau khi được thu thập sẽ tiến hành hiệu chỉnh bức xạ chuyển các giá trị số sang giá trị phản xạ và các công thức hiệu chỉnh này tùy thuộc vào loại ảnh Landsat.

Đối với ảnh Landsat 5:

Các giá trị ở dạng số nguyên được chuyển đổi sang giá trị bức xạ phổ theo công thức [19]:

$$
L_{\lambda}=\frac{L_{M A X}-L_{M I N}}{Q_{C A L M A X}-Q_{C A L M I N}}\left(Q_{C A L}-Q_{C A L M I N}\right)+L_{M I N}
$$

Trong đó $L_{\lambda}$ là giá trị bức xạ phổ $\left(\mathrm{w} /\left(\mathrm{m}^{2} . \mathrm{sr} . \mu \mathrm{m}\right)\right) ; Q_{C A L}$ là giá trị điểm ảnh hiệu chỉnh định lượng ở dạng số nguyên; QCALMIN, QCALMAX là giá trị điểm ảnh hiệu chỉnh định lượng cực tiểu và cực đại ứng với từng kênh từ thông tin dữ liệu ảnh; $L_{M I N}, L_{M A X}$ là các giá trị bức xạ phổ cực tiểu và cực đại ứng với từng kênh từ thông tin dữ liệu ảnh $\left(\mathrm{w} /\left(\mathrm{m}^{2} . \mathrm{sr} . \mu \mathrm{m}\right)\right)$.

Sau khi tính được giá trị bức xạ phổ của từng kênh, giá trị phản xạ phổ của từng kênh được tính theo công thức sau [19]:

$$
\rho_{P}=\frac{\pi L_{\lambda} d^{2}}{E S U N_{\lambda} \sin \theta}
$$

Trong đó $\rho_{P}$ là giá trị phản xạ phổ; $L_{\lambda}$ là giá trị bức xạ phổ $\left(\mathrm{w} /\left(\mathrm{m}^{2} . \mathrm{sr} . \mu \mathrm{m}\right)\right) ; \mathrm{d}$ là khoảng cách Trái Đất-Mặt Trời (đơn vị thiên văn); $E S U N \lambda$ là cường độ bức xạ Mặt Trời đến khí quyển $\left(\mathrm{w} /\left(\mathrm{m}^{2} \cdot \mu \mathrm{m}\right)\right)($ Bảng 2$) ; \theta$ là góc cao độ Mặt Trời từ thông tin dữ liệu ảnh.

Bảng 2. Chỉ số ESUN入 đối với Landsat 5 theo ChKur [19].

\begin{tabular}{cc}
\hline Kênh & Landsat 5 \\
\hline 1 & 1957 \\
2 & 1826 \\
3 & 1554 \\
4 & 1036 \\
5 & 215 \\
7 & 80,67 \\
\hline
\end{tabular}


Đối với Landsat 8:

Việc tính toán giá trị phản xạ phổ đối với Landsat 8 không có mối liên hệ với giá trị bức xạ phồ, nên có thể bỏ qua bước tính giá trị bức xạ phổ của từng kênh mà chuyển sang tính trực tiếp theo các công thức sau [20]:

$$
\rho_{\lambda}^{\prime}=M_{\rho} Q_{C A L}+A_{\rho}
$$

Trong đó $\rho_{\lambda}^{\prime}$ là giá trị phản xạ phổ khi không hiệu chỉnh góc nghiêng Mặt Trời; $M_{\rho}, A_{\rho}$ là hệ số tỉ lệ ứng với từng kênh từ thông tin dữ liệu ảnh; $Q_{C A L}$ là giá trị điểm ảnh ở dạng số nguyên.

Khi có tính đến góc nghiêng của Mặt Trời thì giá trị của phản xạ phổ được tính theo công thức [20]:

$$
\rho_{\lambda}=\frac{\rho_{\lambda}^{\prime}}{\sin \theta}
$$

Trong đó $\rho_{\lambda}$ là giá trị phản xạ phổ; $\theta$ là góc cao độ Mặt Trời từ thông tin dữ liệu ảnh.

Bảng 3. Khóa giải đoán cho 3 loại đối tượng.

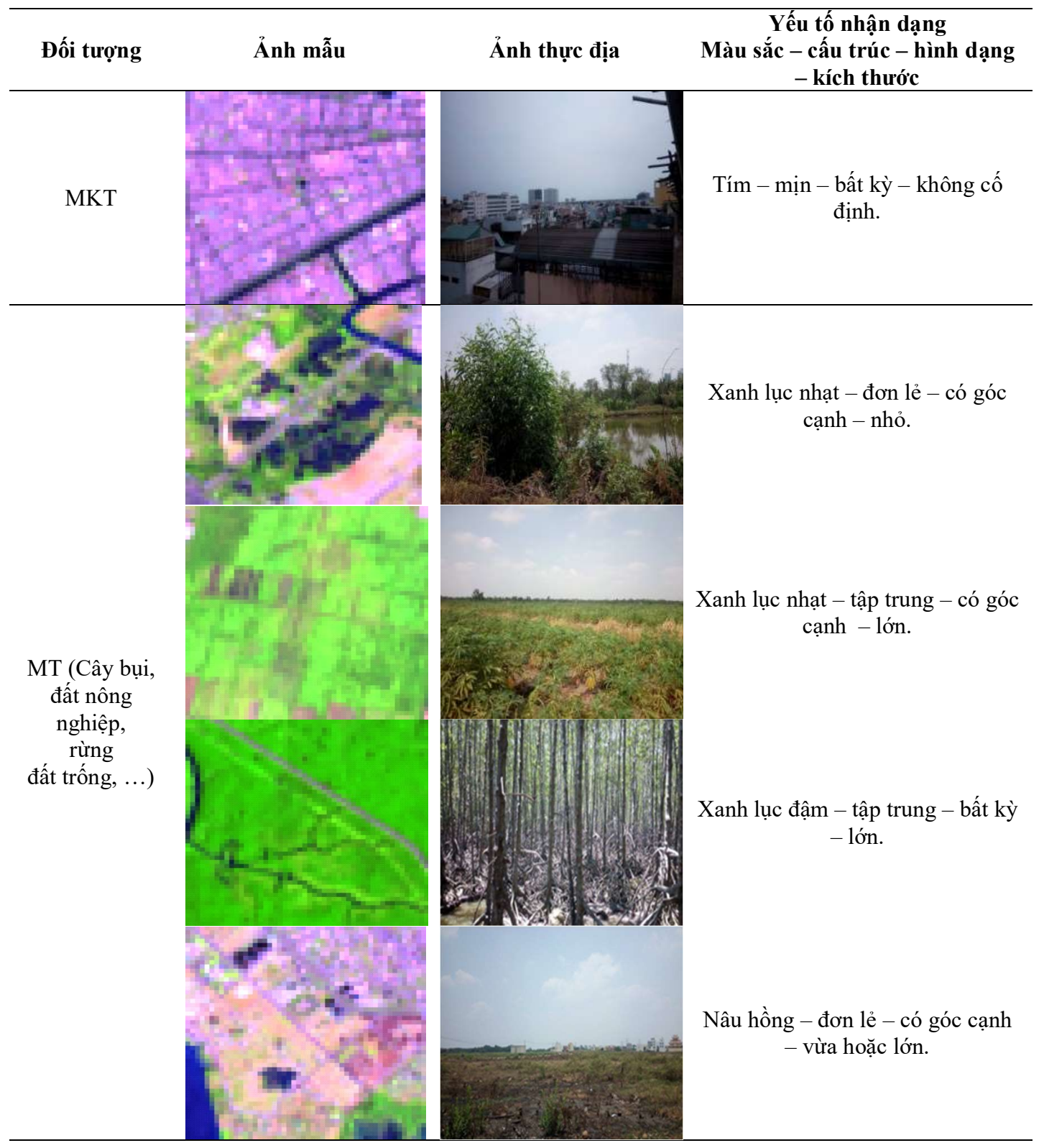




\begin{tabular}{|c|c|c|c|}
\hline Đối tượng & Ảnh mẫu & Ảnh thực địa & $\begin{array}{c}\text { Yếu tố nhận dạng } \\
\text { Màu sắc - cấu trúc - hình dạng } \\
\text { - kích thước }\end{array}$ \\
\hline Mặt nước & & & $\begin{array}{l}\text { Xanh dương - mịn - bất kỳ - } \\
\text { không cố định. }\end{array}$ \\
\hline
\end{tabular}

Sau khi tính giá trị phản xạ, các ảnh này được nắn chỉnh hình học, lập ảnh tỉ số và tiến hành ghép các kênh lại với nhau. Các dữ liệu này kết hợp với dữ liệu GIS để cắt ảnh theo khu vực nghiên cứu sau đó tiến hành tạo mẫu huấn luyện. Nghiên cứu quan tâm đến đối tượng đô thị thông qua MKT nên sẽ tạo ba mẫu huấn luyện gồm: MKT bao gồm các bề mặt nhân tạo như mái nhà, đường giao thông, lối đi bộ,... được bao phủ bởi các MKT như bê tông, nhựa đường, đá và các vật liệu xây dựng khác; MT là các đối tượng tự nhiên bao gồm thực vật và đất tự nhiên khác; Nước bao gồm sông, ao, hồ, đầm lầy,... Các mẫu huấn luyện này có những đặc trưng riêng khi sử dụng tổ hợp màu giả 543 với ảnh Landsat 5 và 654 đối với ảnh Landsat 8 (chi tiết có thể xem trong Bảng 3 ). Tiếp theo tiến hành phân loại dựa vào các mẫu huấn luyện này bằng cách sử dụng phương pháp phân loại có kiểm định xác suất cực đại (Maximum Likelihood Classification). Các kênh ảnh dùng để phân loại bao gồm: tất cả các kênh phản xạ nằm trong dải từ kênh khả kiến đến hồng ngoại [2] (đối với Landsat 5 gồm 6 kênh từ kênh 1 đến kênh 7 bỏ kênh 6 còn đối với Landsat 8 gồm 7 kênh từ kênh 2 đến kênh 9 bỏ kênh 8 ); ảnh tỉ số NIR/green (kênh 4/kênh 2 đối với Landsat 5 và kênh $5 /$ kênh 3 đối với Landsat 8); ảnh tỉ số MIR/green (kênh 5/kênh 2 đối với Landsat 5 và kênh 6/kênh 3 đối với Landsat 8).

Kết quả phân loại được đánh giá độ chính xác thông qua dữ liệu thực địa và Google Earth cho độ tin cậy cao với độ chính xác toàn cục và hệ số Kappa lần lượt là $94,28 \%$ và 0,91 (2019). Các thời điểm còn lại do không có dữ liệu thực đo gần với thời điểm đó nên được đánh giá qua phương pháp kết hợp khảo sát trực quan trên ảnh vệ tinh và ảnh lịch sử trên Google Earth với hệ số Kappa lần lượt là 0,85 (1989), 0,89 (1998), 0,88 (2010). Nghiên cứu cũng so sánh với số liệu diên tích đất vào các năm 2000, 2011, 2018 [21-23]. Năm 2000 diện tích đất ở là 16686ha trong khi đó kết quả diện tích MKT năm 1998 là 9805,8ha. Kết quả diện tích MKT có thể là do diện tích đất ở theo thống kê bao gồm cả diện tích đất chưa xây dựng. Đến năm 2010 diện tích MKT là 29624,1 ha trong khi đó diện tích đất ở theo thống kê năm 2011 là 23700 ha. Diện tích MKT cao hơn so với diện tích đất ở có thể ngoài diện tích MKT nằm trong diện tích đất ở còn có diện tích MKT thuộc các loại đất chuyên dụng khác. Tương tự diện tích MKT năm 2019 là 40215,3 ha trong khi đó diện tích đất ở thống kê năm 2018 là 28700 ha. Thêm vào đó nghiên cứu cũng có so sánh ảnh phân loại năm 2019 với điểm mẫu khảo sát thực tế năm 2018 thì kết quả cũng rất phù hợp. Như vậy các kết quả phân loại đáng tin cậy nên các kết quả này được chuyển sang dữ liệu vector để xử lý trên GIS.

GIS

Các kết quả phân loại được sử dụng để chồng lớp bản đồ, thống kê, phân tích biến động trên GIS. Tất cả các dữ liệu này được lưu trữ ở dạng vector dưới định dạng “.shp” giúp thuận tiện trong quá trình xử lý, phân tích, đánh giá và thành lập bản đồ sau này.

\section{Kết quả và thảo luận}

\subsection{Kết quả phân loại năm 1989, 1998, 2010 và 2019}




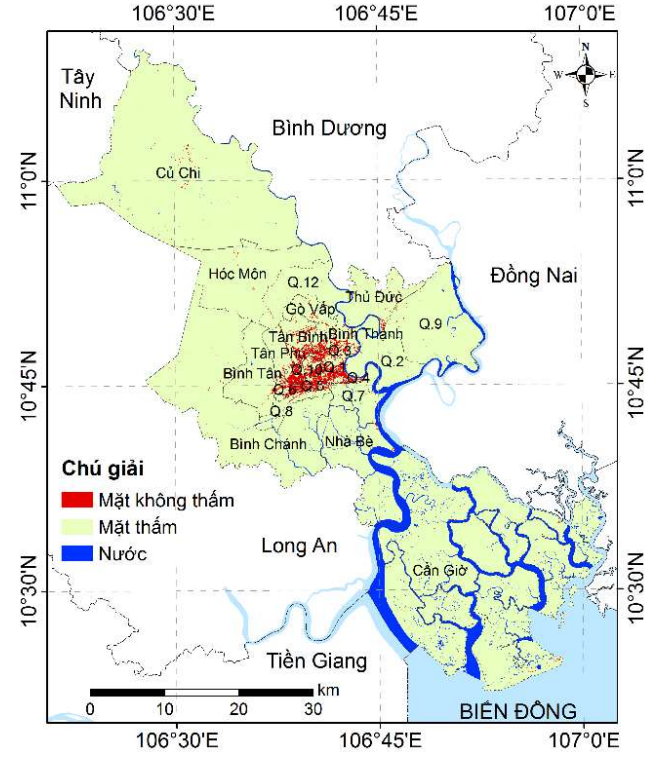

a. 1989

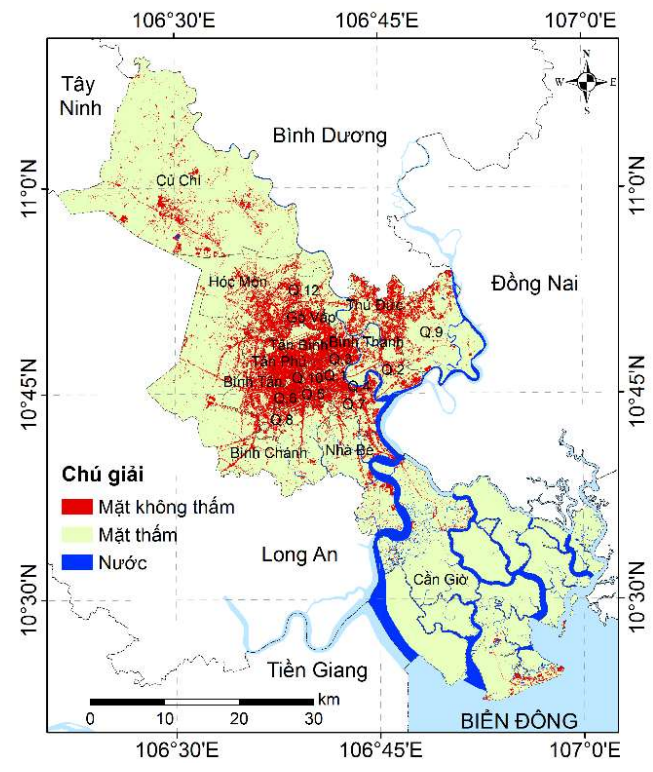

c. 2010

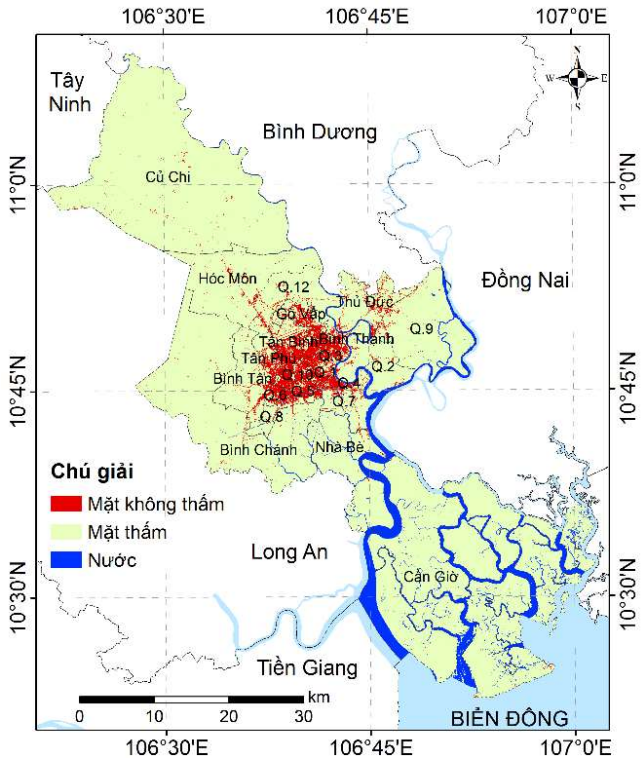

b. 1998

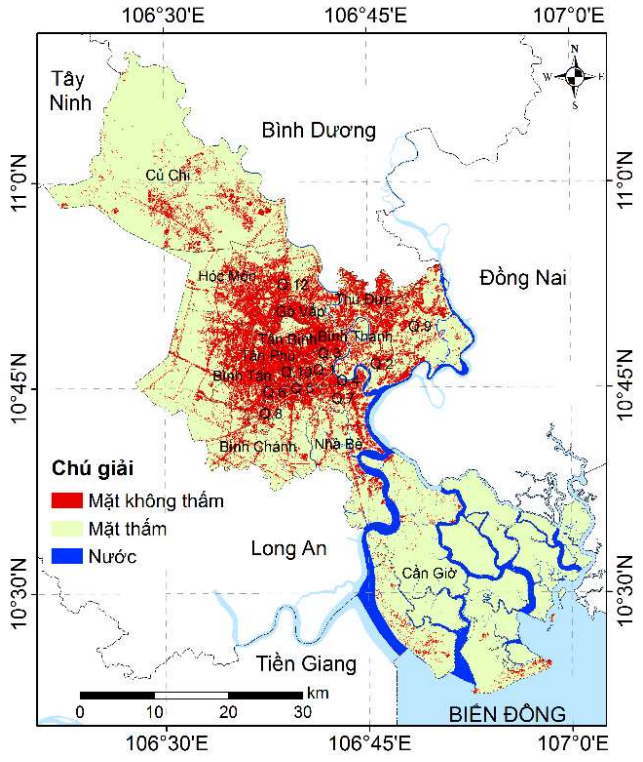

d. 2019

Hình 4. Bản đồ phân loại các đối tượng tại thành phố Hồ Chí Minh qua các năm.

Từ các bản đồ phân loại các đối tượng cho thấy phân bố MKT ở thành phố Hồ Chí Minh không đều tập trung chủ yếu tại các khu vực nội thành (Hình 4). Theo thời gian tại thành phố Hồ Chí Minh có sự phân bố lại các khu đô thị với sự mở rộng thêm các khu đô thị cũ đã có từ những năm trước và xuất hiện thêm những khu đô thị mới ở các khu vực ven nội thành và ngoại thành. Các khu đô thị đang có xu hướng phát triển mạnh từ khu vực nội thành tiến dần lên phía bắc, đông bắc và tây bắc thành phố với mật độ đô thị ngày càng dày đặc ở các khu vực nội thành và thưa thớt ở ngoại thành. Về phân bố không gian đô thị nếu xét theo phân chia đơn vị hành chính quận, huyện thì năm 1989 các khu đô thị tập trung chủ yếu ở tám quận nội thành bao gồm quận $1,3,4,5,6,10,11$, Phú Nhuận và xuất hiện thêm 3 khu đô thị hóa tại quận 8 , Tân Bình, Bình Thạnh. Sự tập trung các khu đô thị hóa tại ba quận này vẫn còn thưa thớt (Hình 4a). Đến năm 1998 ngoài các khu đô thị đã có từ năm 1989 phát triển mạnh, ngày càng dày đặc còn xuất hiện thêm các khu đô thị mới ở quận 7 , Tân Phú, Gò Vấp, Thủ Đức và một vài nơi ở quận 12, Bình Tân (Hình 4b). Tương tự đến năm 2010 các khu đô thị cũ từ năm 1998 tiếp tục mở rộng và phát triển và xuất hiện thêm các khu đô thị ở các 
quận, huyện vùng ven như quận 2, 9, huyện Bình Chánh, Hóc Môn và Nhà Bè với xu hướng ở các quận trung tâm mật độ đô thị ngày càng dày đặc còn những quận, huyện mới vẫn còn thưa thớt (Hình 4c). Đến năm 2019 thì quá trình đồ thị hóa đều xảy ra ở tất cả các quận, huyện ngoại trừ huyện Cần Giờ, Nhà Bè, Củ Chi có lớp đô thị phân bố rải rác tại các trục đường chính và tại các khu công nghiệp, dân cư (Hình $4 \mathrm{~d})$. Quá trình đô thị hóa ở thành phố Hồ Chí Minh có xu hướng mở rộng từ trung tâm ra các quận, huyện ngoại thành đặc biêt phát triển mạnh lên phía bắc, tây bắc và đông bắc thành phố.

\subsection{Phân tích biến động diện tích qua các năm 1989, 1998, 2010, 2019}

Kết quả từ Hình 5 cho thấy có sự thay đổi theo chiều hướng tăng diện tích MKT, giảm diện tích MT và diện tích mặt nước hầu như không thay đổi nhiều. Năm 1989 diện tích MKT, MT, nước lần lượt là 3783,6 ha $(1,8 \%), 182827,5$ ha $(87,3 \%), 22894,9$ ha $(10,9 \%)$ trong tổng số diện tích đất toàn thành phố. Diện tích MT ở năm này chiếm tỷ lệ rất lớn, còn diện tích MKT không đáng kể. Đến năm 1998 diện tích MT giảm còn 176020,4 ha chiếm 84\%, diện tích MKT tăng lên 9805,8 ha chiếm 4,7\% đối với MKT và diện tích mặt nước chiếm khoảng $11,3 \%$. Năm 2010 được xem là năm bùng nổ đô thị với diện tích MKT lúc này là 29624,1 ha chiếm 14,1\% gấp 3 lần so với năm 1998, diện tích MT giảm đáng kể còn 157156,8 ha $(75 \%)$ và diện tích mặt nước cũng giảm còn 22725 ha $(10,9 \%)$. Sự bùng nổ này một phần là do chuyển đổi mục đích sử dụng đất từ đất nông nghiệp sang đất xây dựng trong những thời kỳ sốt đất đai, hoạt động bất động sản diễn ra mạnh mẽ làm cho đất đô thị tăng nhanh, một phần do sự bùng nổ dân số từ sự nhập cư từ vùng nông thôn vào thành thị. Đến năm 2019 , diện tích MKT đã là 40215,3 ha chiếm 19,2\%, MT là 147862,9 ha chiếm 70,6\% trong tổng diện tích đất tự nhiên của toàn thành phố. Có thể thấy trong quá trình đô thị hóa từ năm 1989 đến năm 2019, sau một quá trình dài dịch chuyển cơ cấu sử dụng đất thì diện tích MKT tính đến năm 2019 được thêm vào $17,4 \%$ diện tích còn MT bị lấy mất $16,7 \%$ diện tích từ năm 1989 (Hình 6). Nếu không xét diện tích Cần Giờ thì diện tích MKT năm 2019 chiếm tới 28\% tổng diện tích. Sự biến động theo không gian của MKT năm 2019 so với năm 1989 được thể hiện rõ trong Hình 7 cho thấy MKT có xu hướng mở rộng ra khu vực xung quanh đặc biệt là phía bắc, đông bắc và tây bắc thành phố. Trong vòng 30 năm diện tích MKT đã tăng 36431,7 ha tương ứng với tốc độ tăng trung bình 1214,4 ha/năm.

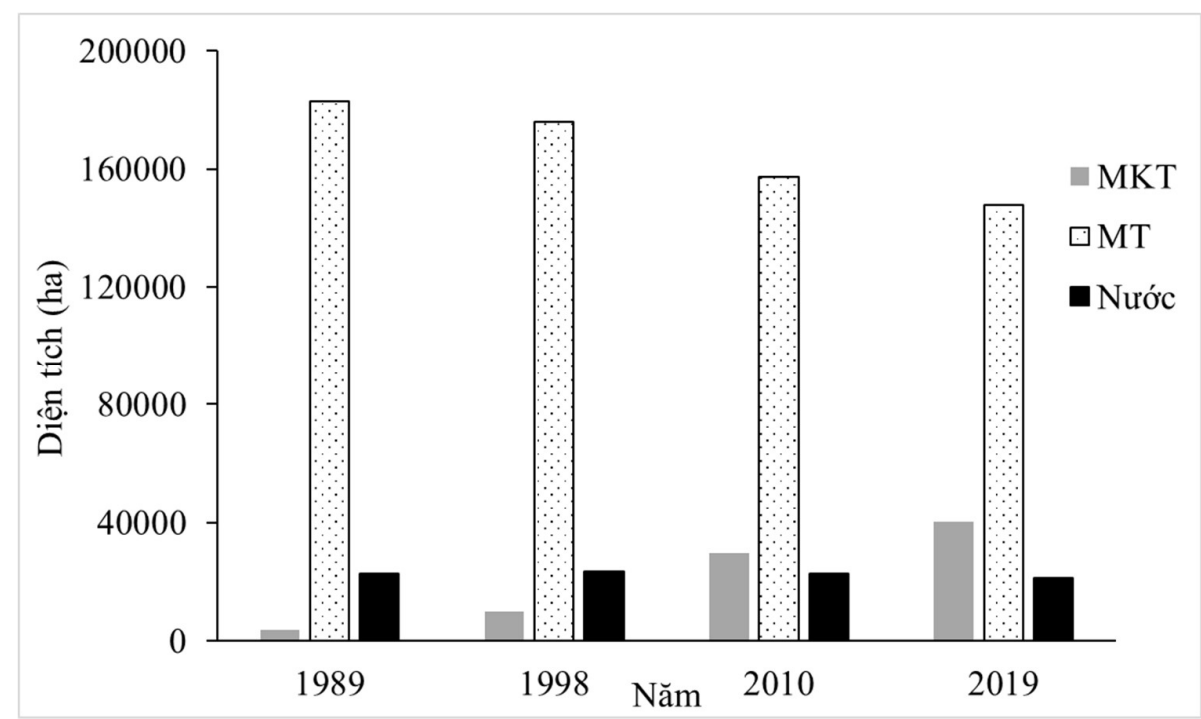

Hình 5. Biểu đồ cơ cấu các đối tượng qua các năm 1989, 1998, 2010, 2019 tại thành phố Hồ Chí Minh. 


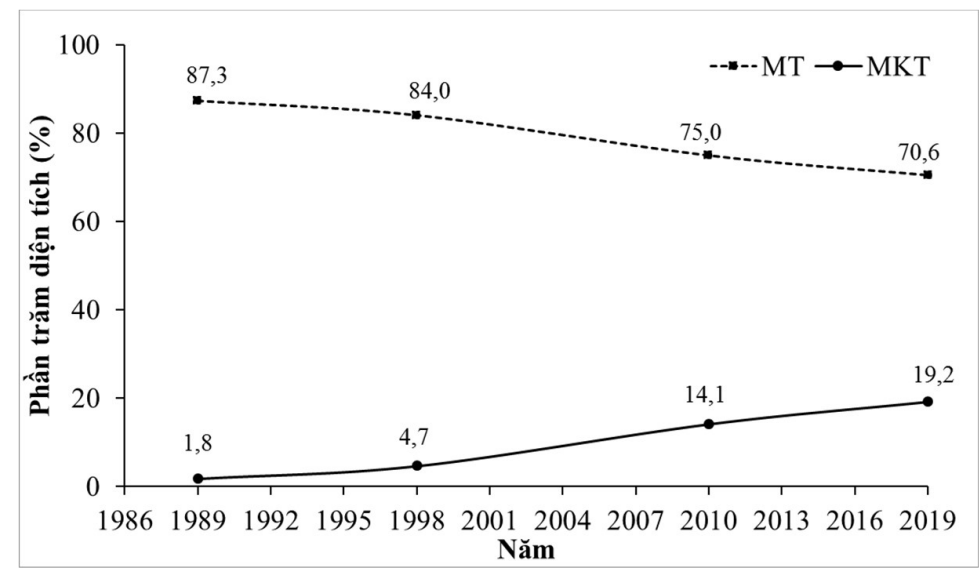

Hình 6. Phần trăm diện tích MT, MKT qua các năm 1989, 1998, 2010, 2019 tại thành phố Hồ Chí Minh.

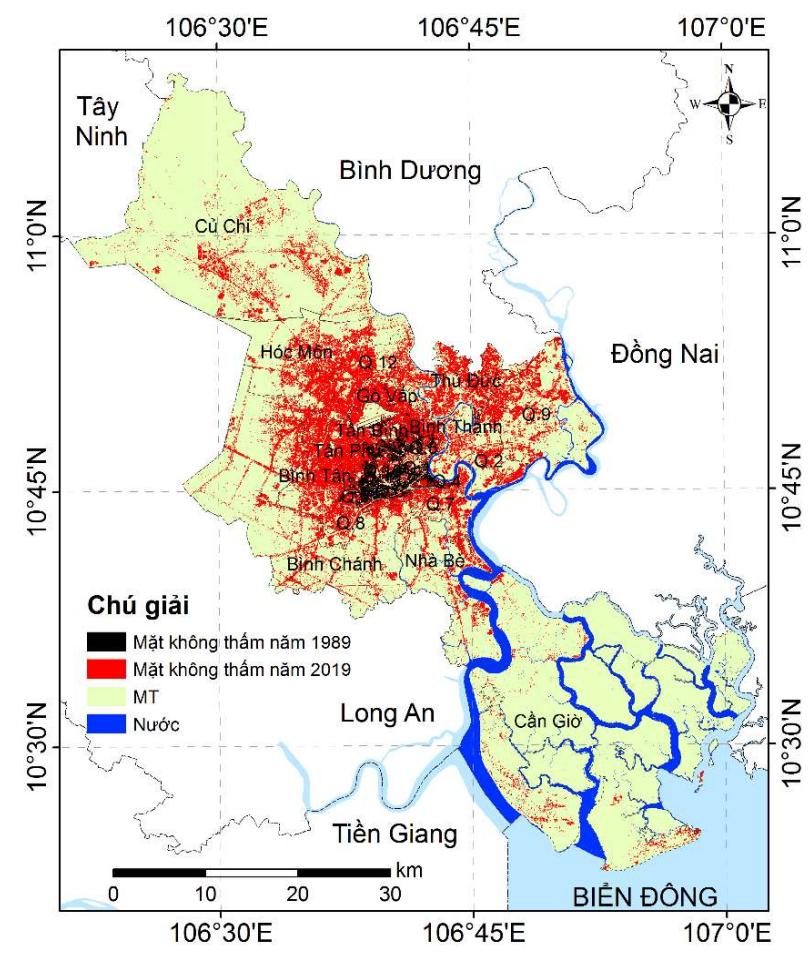

Hình 7. Bản đồ phân bố MKT tại thành phố Hồ Chí Minh năm 2019 so với năm 1989.

Bảng 4. Thống kê phần trăm diện tích MKT so với tổng diện tích từng quận, huyện qua các năm.

\begin{tabular}{crrrrlrrrr}
\hline $\begin{array}{c}\text { Quận, } \\
\text { huyện }\end{array}$ & $\begin{array}{r}\mathbf{1 9 8 9} \\
\mathbf{( \% )}\end{array}$ & $\begin{array}{r}\mathbf{1 9 9 8} \\
\mathbf{( \% )}\end{array}$ & $\begin{array}{r}\mathbf{2 0 1 0} \\
\mathbf{( \% )}\end{array}$ & $\begin{array}{r}\mathbf{2 0 1 9} \\
\mathbf{( \% )}\end{array}$ & $\begin{array}{c}\text { Quận, } \\
\text { huyện }\end{array}$ & $\begin{array}{r}\mathbf{1 9 8 9} \\
\mathbf{( \% )}\end{array}$ & $\begin{array}{r}\mathbf{1 9 9 8} \\
\mathbf{( \% )}\end{array}$ & $\begin{array}{r}\mathbf{2 0 1 0} \\
\mathbf{( \% )}\end{array}$ & $\begin{array}{r}\mathbf{2 0 1 9} \\
\mathbf{( \% )}\end{array}$ \\
\hline 1 & 47,2 & 63,9 & 69,2 & 68,8 & Bình Chánh & 0,1 & 0,6 & 9,3 & 18,0 \\
2 & 0,3 & 3,2 & 23,5 & 31,9 & Bình Tân & 0,7 & 6,2 & 49,7 & 66,5 \\
3 & 54,2 & 79,1 & 83,6 & 79,2 & Bình Thạnh & 12,3 & 43,2 & 55,2 & 57,9 \\
4 & 49,1 & 76,1 & 82,8 & 77,0 & Cần Giờ & 0,1 & 0,1 & 1,2 & 1,7 \\
5 & 72,1 & 78,3 & 83,5 & 79,1 & Củ Chi & 0,2 & 0,4 & 5,7 & 8,2 \\
6 & 42,3 & 70,3 & 91,0 & 88,8 & Gò Vấp & 3,4 & 38,4 & 71,0 & 80,6 \\
7 & 1,9 & 10,4 & 39,2 & 44,9 & Hóc Môn & 0,2 & 1,8 & 16,3 & 29,6 \\
8 & 13,7 & 27,6 & 58,5 & 63,0 & Nhà Bè & 0,2 & 0,7 & 10,8 & 15,6 \\
9 & 0,3 & 1,9 & 16,0 & 27,3 & Phú Nhuận & 40,0 & 77,0 & 83,4 & 81,9 \\
10 & 46,3 & 75,0 & 80,4 & 81,5 & Tân Bình & 21,6 & 53,0 & 63,5 & 65,7 \\
11 & 57,1 & 81,2 & 86,1 & 83,9 & Tân Phú & 4,1 & 38,8 & 81,5 & 86,1 \\
12 & 0,3 & 6,2 & 36,8 & 58,1 & Thủ Đức & 1,6 & 10,8 & 44,7 & 59,9 \\
\hline
\end{tabular}


Xét theo đơn vị hành chính thì năm 1989 diện tích MKT tại tám quận nội thành chiếm tỉ lệ cao trên $40 \%$ đó là Quận $1,3,4,5,6,10,11$, Phú Nhuận (Bảng 4). Quận 5 có phần trăm diện tích MKT cao nhất trong tám quận này với $72,1 \%$ và quận Phú Nhuận có phần trăm diện tích MKT thấp nhất với $40 \%$. Như vậy trong thời gian này 8 quận kể trên đã là những khu vực đô thị và nếu lấy quận 3 làm trung tâm thì bán kính của khu vực đô thị này là khoảng $6 \mathrm{~km}$. Cũng trong thời gian này các quận 8 , Bình Thạnh, Tân Bình bắt đầu có quá trình đô thị hóa với phần trăm diện tích MKT lần lượt là $13,7 \%, 12,3 \%$ và 21,6\%. Đến năm 1998 diện tích MKT tại tám quận nội thành tiếp tục được mở rộng nhanh với tỉ rất cao trên $60 \%$ trong đó quận 11 có tỉ lệ cao nhất $(81,2 \%)$ và quận 1 có tỉ lệ thấp nhất $(63,9 \%)$. Quận 8 , Bình Thạnh và Tân Bình có quá trình đô thị hóa tiếp tục diễn ra mạnh mẽ với tỉ lệ diện tích MKT lần lượt là $27,6 \%, 43,2 \%$ và $53 \%$. Trong thời gian này bán kính khu vực đô thị đã tăng đến $7 \mathrm{~km}$. Ngoài ra, cũng trong thời gian này quá trình đô thị hóa cũng bắt đầu diễn ra tại các quận vùng ven đó là quận $7(10,4 \%), 12$ (6,2\%), Bình Tân $(6,2 \%)$, Gò Vấp (38,4\%), Tân Phú $(38,8 \%)$, Thủ Đức (10,8\%). Năm 2010 diện tích MKT tại 17 quận kể trên tiếp tục được mở rộng và phát triển với phần trăm diện tích MKT cao nhất và thấp nhất lần lượt tại quận $6(91 \%)$, quận $12(36,8 \%)$ và bán kính khu vực đô thị lên đến $17 \mathrm{~km}$. Quá trình đô thị hóa tiếp tục mở rộng ra các quận, huyện khác như quận $2(23,5 \%), 9$ (16\%), Bình Chánh $(9,3 \%)$, Hóc Môn $(16,3 \%)$, Nhà Bè $(10,8 \%)$. Quá trình đô thị hóa diễn ra tại hầu hết các quận, huyện trong năm 2019 ngoại trừ các huyện ngoại thành có tỉ lệ MKT thấp đó là huyện Cần Giờ $(1,7 \%)$, Củ Chi $(8,2 \%)$, Nhà Bè $(15,6 \%)$ và bán kính khu vực đô thị đã mở rộng lên đến 19 km.

Cùng với quá trình đô thị hóa thành phố Hồ Chí Minh là quá trình phân bố lại dân cư của thành phố. Nếu như trong hai thời kỳ 1979-1989 và 1989-1999 dân số thành phố tăng chủ yếu do yếu tố tự nhiên thì trong những năm gần đây dân số thành phố tăng chủ yếu là tăng cơ học $[24,25]$. Với nhu cầu việc làm tăng cao, lượng dân cư từ các vùng miền đổ về thành phố ngày một đông và có xu hướng các dòng dân cư dịch chuyển từ các quận nội thành ra các quận, huyện vùng ven. Điều này đòi hỏi phải tập trung đầu tư xây dựng nhà ở, cơ sở hạ tầng và các công trình kiến trúc cho các quận, huyện mới này nhằm cải thiện đời sống đô thị và tạo bộ mặt đô thị phát triển toàn diện.

\section{Kết luận}

Sự phân bố không gian của đô thị thông qua các bề mặt không thấm qua các năm tại thành phố Hồ Chí Minh không đồng đều. Trong vòng 30 năm từ năm 1989 đến năm 2019, khu vực đô thị phát triển mạnh theo hướng mở rộng từ khu vực trung tâm ra các khu vực xung quanh và có xu hướng tiến dần lên phía bắc, đông bắc và tây bắc của thành phố. Các khu đô thị có xu hướng mở rộng diện tích theo không gian, phủ kín gần hết quỹ đất ở khu vực nội thành và đang tiến dần ra các khu vực lân cận và ngoại ô thành phố. Khu vực ngoại thành đã và đang xuất hiện thêm các khu đô thị mới. Quá trình đô thị hóa ở thành phố Hồ Chí Minh diễn ra ngày càng mạnh mẽ thông qua diện tích MKT ngày càng tăng với phần trăm diện tích qua các năm 1989, 1998, 2010, 2019 lần lượt là 1,8\%, 4,7\%, 14,1\%, 19,2\% và tốc độ tăng trung bình hàng năm là 1214,4 ha/năm. Kết quả nghiên cứu sẽ là cơ sở hữu ích giúp các nhà quản lý theo dõi biến động và ra các chiến lược phát triển bền vững và cải thiện cuộc sống đô thị, đồng thời cũng giúp ích cho việc xem xét, đánh giá tác động của đô thị hóa lên môi trường sống và sự thay đổi nhiệt độ của đô thị trong bối cảnh biến đổi khí hậu toàn cầu hiện nay.

Đóng góp của tác giả: Xây dựng ý tưởng nghiên cứu: L.V.H.; Lựa chọn phương pháp nghiên cứu: L.V.H., Xử lý và phân tích số liệu: L.V.H., L.T.P.M.; Viểt bản thảo bài báo: L.V.H., L.T.P.M.; Chỉnh sửa bài báo: L.V.H.

Lời cảm ơn: Nghiên cứu được tài trợ bởi Trường Đại học Khoa học Tự nhiên, ĐHQG-HCM trong khuôn khổ Đề tài mã số T2019-08. 
Lò̀i cam đoan: Tập thể tác giả cam đoan bài báo này là công trình nghiên cứu tập thể tác giả, chưa được công bố ở đâu, không được sao chép từ những nghiên cứu trước đây; không có sự tranh chấp lợi ích trong nhóm tác giả

\section{Tài liệu tham khảo}

1. Việt, L.V. Biến đổi khí hậu. NXB Đại học Công nghiệp thành phố Hồ Chí Minh, 2017.

2. Vân, T.T. Ứng dụng viễn thám và GIS giám sát đô thị hóa thành phố Hồ Chí Minh thể hiện qua các mặt không thấm. Tạp chí phát triển Khoa học và Công nghệ 2011, $14,65-77$.

3. Ban chỉ đạo tổng điều tra dân số và nhà ở Trung Ương. Tổng điều tra dân số và nhà ở thời điểm 0 giờ ngày 01 tháng 4 năm 2019: Tổ chức thực hiện và kết quả sơ bộ. NXB Thống kê, 2019.

4. The, Đ.T.; Cự, P.V.; Nhuận, M.T.; Liểu, T.M.; Đương, Đ.V. Ú̉ng dụng Viễn thám và GIS nghiên cứu đô thị hóa thành phố Đà Nẵng và mối quan hệ của đô thị hóa trong xây dựng thành phố có khả năng ứng phó với biến đổi khí hậu. Báo cáo Hội nghị Ứng dụng GIS toàn quốc 2015, 570-576.

5. Hoa, Đ.T.B. Nghiên cứu mật độ đô thị Hà Nội và bề mặt không thấm bằng công nghệ viễn thám và GIS. Tạp chí Khoa học, Truờng Đại học Su phạm Hà Nội 2015, 144 151.

6. Trung, L.V.; Vũ, N.N. Ứng dụng viễn thám và GIS đánh giá xu thế đô thị hóa tại thành phố Cần Thơ. Tạp chí Phát triển Khoa học \& Công nghệ 2018, 2, 57-62.

7. $\mathrm{Xu}, \mathrm{H}$. A new index for delineating built-up land features in satellite imagery. Int. J. Remote Sens. 2008, 29, 4269-4276. http://dx.doi.org/10.1080/01431160802039957.

8. $\mathrm{Xu}, \mathrm{H}$. Analysis of Impervious Surface and its Impact on Urban Heat Environment using the Normalized Difference Impervious Surface Index (NDISI). Photogramm. Eng. Remote Sens. 2010, 76, 557-565. https://doi.org/10.14358/PERS.76.5.557.

9. Sun, Z.; Wang, C.; Guo, H.; Shang, R. A Modified Normalized Difference Impervious Surface Index (MNDISI) for Automatic Urban Mapping from Landsat Imagery. Remote Sens. 2017, 9, 942-960. https://doi.org/10.3390/rs9090942.

10. Garg, A., Pal, D.; Singh, H.; Pandey, D.C. A comparative study of NDBI, NDISI and NDII for extraction of urban impervious surface of Dehradun [Uttarakhand, India] using Landsat 8 imagery. 2016 International Conference on Emerging Trends in Communication Technologies, 2016. https://doi.org/10.1109/ETCT.2016.7882963.

11. Piyoosh, A.K.; Ghosh, S.K. Development of a modified bare soil and urban index for Landsat 8 satellite data. Geocarto Int. 2017, 33, 423-442. doi:10.1080/10106049.2016.1273401.

12. Wang, Z.; Gang, C.; Li, X.; Chen, Y.; Li, J. Application of a normalized difference impervious index (NDII) to extract urban impervious surface features based on Landsat TM images. Int. J. Remote Sens. 2015, 36, 1055-1069. http://dx.doi.org/10.1080/01431161.2015.1007250.

13. Hùng, T.L.; Nga, N.T.T.; Tuyên, V.D.; Phương, B.T. Đánh giá và dự báo biến động đất đô thị khu vực nội thành thành phố Hà Nội bằng tư liệu viễn thám và GIS. Tạp chi Khoa học, Truờng Đại học Su phạm TP. Hồ Chí Minh 2017, 14, 176-187.

14. Hà, L.T.T; Làn, P.T.; Trung, N.V.; Mỹ, V.C.; Cự, P.V. Úng dụng tư liệu viễn thám xác định xu hướng gia tăng bề mặt không thấm ở nông thôn. Tạp chi Khoa học Đo đạc và Bản đồ 2015, 26, 28-35.

15. Barnes, K.B.; Morgan III, J.M.; Roberge, M.C. Impervious surfaces and the quality of natural and built environments, Project to map impervious cover for the entire Chesapeake Bay and Maryland Coastal Bays watersheds, 2001.

16. U.S. Environmental Protection Agency. Draft report on the environment, 2003. 
17. http://www.hochiminhcity.gov.vn/thongtinthanhpho/gioithieu/Lists/Posts/AllPosts. aspx?CategoryId $=17$

18. http://glovis.usgs.gov/

19. Chander, G.; Markham, B. Revised landsat-5 TM radiometric calibration procedures and postcalibration dynamic ranges. IEEE Trans. Geosci. Remote Sens. 2003, 41, 2674-2677. http://dx.doi.org/10.1109/tgrs.2003.818464.

20. Department of the Interior U.S. Geological Survey. Landsat 8 Data User's Handbook, USA, 2016.

21. Tổng cục thống kê. Niên giám thống kê năm 2000. Nhà xuất bản thống kê, Hà Nội, 2001.

22. Tổng cục thống kê. Niên giám thống kê năm 2011. Nhà xuất bản thống kê, Hà Nội, 2012.

23. Tổng cục thống kê. Niên giám thống kê năm 2019. Nhà xuất bản thống kê, Hà Nội, 2020.

24. Phùng, N.K. Biến đổi khí hậu và tác động đến thành phố Hồ Chí Minh. NXB Đại học Quốc gia thành phố Hồ Chí Minh, 2012.

25. Thọ, P.T.X.; Tuyết, P.T.B. Biến động dân số thành phố Hồ Chí Minh giai đoạn 19992009: hiện trạng, nguyên nhân và các giải pháp. Tạp chí Khoa học, Trường Đại học Su phạm TP. Hồ Chí Minh 2017, 32, 16-26.

\title{
Application of remote sensing and GIS to monitor the urbanization process in Ho Chi Minh city in the period 1989-2019
}

\author{
Lam Van Hao ${ }^{{ }^{*}}$, Le Thi Pha Mi ${ }^{1}$ \\ ${ }^{1}$ Faculty of Physics and Engineering Physics, University of Science, Vietnam National \\ University, Ho Chi Minh city; lvhao@hcmus.edu.vn.
}

\begin{abstract}
This study interpreted Landsat satellite image by using ENVI and ArcGIS software to monitor the process of urbanization in Ho Chi Minh City in the period 19892019 through impervious surfaces with a Kappa coefficient above 0.85 . The research results showed that urban tended to widen from the city center to suburban and tended to spread to the north, the northeast, and the northwest of the city focused particularly on main roads in suburban areas. The impervious surface area increased 36431.7ha with an average growth rate of $1214.4 \mathrm{ha} /$ year. Also, the urban area's radius was expanded from $7 \mathrm{~km}$ to $19 \mathrm{~km}$ in the period 1989-2019.
\end{abstract}

Keywords: Impervious surfaces; Urbanization; Ho Chi Minh City; Remote sensing; GIS. 